\title{
As narrativas em medicina: contribuições à prática clínica e ao ensino médico
}

\section{The narratives in medicine: contributions to medical practice and medical teaching}

\author{
Eloísa Grossman ${ }^{1}$ \\ Maria Helena Cabral de Almeida Cardoso ${ }^{2}$
}

PALAVRAS-CHAVE

- Medicina Narrativa;

- Medicina na Literatura;

- Educação Médica.

\section{KEY-WORDS}

- Narrative Medicine;

- Medicine in Literature;

- Education, Medical.

Recebido em: 26/07/2005

Aprovado em: 18/11/2005

6 REVISTA BRASLEIRA DE EDUCAÇÃO MÉDICA 6 Rio de Janeiro, $v .30, n^{\circ} 1$, jan./abr. 2006

\section{ABSTRACT}

This article discusses the role played by medical narratives. After explanatory research and careful content analysis of the material published about the subject it was possible to conclude that medical narratives are a major issue for those physicians and scholars concerned with the immediate future of medical education. To encompass the broad range of articles and books about the subject, this article was divided into three parts for a better presentation of the presenthy most common forms of discussion around the issue. In the first part we elaborate a classification of medical narratives; the second highlights the links between Medicine and Literature, considered a fundamental tool for the improvement of narrative competence, so necessary for the diagnostic process based on the history of the disease narrated by the patient.Finally we discuss the today's positioning of specialists with respect to the role of the narrative in the field of medical ethics. It also points out that a narrative epistemology has always been contained in medical education and practice.

\footnotetext{
${ }^{1}$ Doutoranda da Pós-Graduação em Saúde da Criança e da Mulher, Instituto Fernandes Figueira, Fundação Oswaldo Cruz , Médica do Núcleo de Estudos da Saúde do Adolescente da Universidade do Estado do Rio de Janeiro., Professora Assistente, Faculdade de Ciências Médicas, Universidade do Estado do Rio de Janeiro, Rio de Janeiro, Brasil.

${ }^{2}$ Professora da Pós-graduação em Saúde da Criança e da Mulher do Instituto Fernandes Figueira, Fundação Oswaldo Cruz. Pesquisadora do Departamento de Genética Médica José Carlos Cabral de Almeida, Instituto Fernandes Figueira, Fundação Oswaldo Cruz, Rio de Janeiro, Brasil.
} 
“Escrever é procurar entender, é procurar reproduzir o irreproduzível, é sentir até o último fim o sentimento que permaneceria apenas vago e sufocador.

Escrever é também abençoar uma vida que não foi abençoada."

(Clarice Lispector)

\section{INTRODUÇÃO}

Ao se ler a citação de Clarice Lispector vem à mente a idéia da escrita de uma história que conta fatos e eventos para situar a experiência vivida cortada pelas emoções e sentimentos. E em toda história está implícita a importância da narrativa na estruturação da vida humana.

A narrativa é uma forma lingüística caracterizada, dentre outros aspectos, por: apresentar uma seqüência finita e longitudinal de tempo; pressupor a existência de um narrador e de um ouvinte, cujas visões de mundo estão embutidas no como as histórias são contadas; preocupar-se com os indivíduos e como eles se sentem assim como as pessoas se sentem a respeito deles; prover itens de informação não diretamente pertencentes ao desenrolar dos acontecimentos e, finalmente, engajar o ouvinte e o convidar a uma interpretação. $\mathrm{O}$ ato de narrar é, na realidade, um movimento do presente para o passado no qual a descrição de ações e acontecimentos torna possível refletir sobre si mesmo para se auto compreender e explicar-se ${ }^{1}$.

Hoje há forte sustentação acadêmica da importância do estudo das narrativas como uma atividade central na prática e ensino da Medicina ${ }^{2}$. Conceitualmente, Medicina e narrativa caminham juntas visto que múltiplas possibilidades narrativas são geradas pela doença: o adoecimento por ele mesmo, inscrito nos corpos; a descrição autobiográfica dos pacientes; a transformação dos relatos destes pelos médicos e o próprio curso da doença, expondo relações entre linguagem, soma, indivíduo e tempo ${ }^{3}$.

A interpretação médica cria metahistórias das doenças, a partir dos componentes das narrativas dos pacientes e da observação de sinais. As histórias e os eventos que se sucedem nas enfermidades são transmutados em narrativas médicas, pedras fundamentais para o entendimento da complexidade dos processos humanos de adoecimento isto é, a possibilidade de entender uma história no contexto de outras histórias ${ }^{4}$.

Literatura e Medicina compartilham uma longa trajetória de polinização cruzada ${ }^{5}$. Confrontados com a experiência perturbadora da doença, os grupos humanos criam modelos para explicar o seu surgimento, a cura ou a morte. Os textos literários captam, através da delicadeza dos autores, as idéias e valores de uma sociedade sobre saúde, doença e Medicina. Às ve- zes são relatos de experiências pessoais, outras, narrativas sobre doenças e Medicina e, ainda, de forma menos objetiva, em alguns, a doença pode funcionar como metáfora da cultura6 ${ }^{6}$. Como na ficção, os relatos médicos de cada caso particular envolvem subjetividades autorais, visto que o material é selecionado e organizado com o intuito de adquirir coerência e inteligibilidade. Em conseqüência, os registros de anamneses em prontuários e as descrições de casos clínicos englobam reflexão, interpretação, elucubração e pontos de vistas subjetivos.

Nas últimas duas décadas um outro aspecto vem sendo valorizado por profissionais de saúde, pacientes e estudiosos de ética: as narrativas e a ética médica7. Embora a doença seja um fenômeno biológico e material, a resposta humana a esse evento não é biologicamente determinada ou aritmeticamente traduzível. A singularidade de cada caso emerge no ato de narrar. Para percebê-la, o profissional necessita ser competente para seguir o fio da narrativa do paciente, dar sentido à sua linguagem simbólica, compreender o significado das histórias e imaginar a doença pela perspectiva do doente, muitas vezes contraditória. A forma como o paciente fala de sua doença, o modo como o médico a representa em palavras, quem a escuta nas discussões clínicas, o que a audiência é movida a sentir e pensar são dimensões éticas profundas envolvidas nos cuidados à saúde das pessoas.

A Medicina, ancorada nos princípios das ciências biológicas, é um corpo prático de conhecimentos construídos a partir do entendimento de casos particulares. Como assegura Hunter", pode ser definida como uma "ciência de indivíduos", reportando-se não exclusivamente aos modos de escuta necessários ao diagnóstico, mas configurando-se num saber construído na prática que, sem abrir mão da razão científica, não está distanciado dos efeitos da experiência de adoecimento na vida do paciente e de seus familiares, situando a doença em um contexto maior da existência humana.

Este artigo, situado no vórtice da proliferação supersônica dos recursos tecnobiológicos de diagnóstico e tratamento das doenças, focaliza as discussões atuais sobre o papel das narrativas em Medicina, partindo de fontes bibliográficas cujo objeto é a formação médica no novo milênio. Sua apresentação foi estruturada em três partes distintas, embora articuladas. São discutidas as diferentes modalidades narrativas em Medicina, os argumentos para a articulação entre Literatura e Medicina nos currículos médicos e as possibilidades de inserção desse campo como método de ensino-aprendizagem e, finalmente, o papel da narrativa na ética médica, cada dia mais imprescindível diante de uma saúde que está sendo vista como um bem a ser autogerido, com base nos recursos disponíveis numa sociedade de mercado globalizado. 


\section{AS DIFERENTES MODALIDADES NARRATIVAS EM MEDICINA}

Rita Charon ${ }^{8}$ chama atenção para a necessidade da competência narrativa dos profissionais direta ou indiretamente ligados aos cuidados médicos. Embora sua ênfase recaia sobre a interação médico-paciente, suas proposições ultrapassam o restrito ambiente da consulta para focar os elementos que corroboram a perspectiva da narrativa como central aos processos de saúde e adoecimento. Uma doença, segundo Charon, tem seu tempo característico de curso, uma complexa mistura de contingência e causalidade, particularidades e similitudes comuns a outras doenças, uma tradição textual dentro da qual pode ser compreendida e um sistema metafórico que a desvenda. Foi levando em consideração esses elementos que se empreendeu uma tentativa de sistematizar as formas de narrativas presentes no campo de formação/informação médica.

\section{1 - Casos construídos com propostas educativas}

O método PBL (Problem Based Learning - Aprendizado Baseado em Problemas) é uma estratégia didático-pedagógica centrada no aluno. Foi desenvolvido objetivando substituir aulas expositivas descontextualizadas do mundo real. Tem sido aplicado em escolas médicas nos últimos 30 anos e trata-se de método de eficiência comprovada por pesquisas no campo da psicopedagogia e da avaliação de desempenho dos profissionais por ele formados. O problema é o elemento central; um bom problema deve ser simples, objetivo, motivador, propor situações sobre as quais o aluno possua algum conhecimento prévio ou já tenha vivenciado na prática. Propõe-se a formar profissionais autônomos, capazes de relacionar teoria e prática e, especialmente, aptos a buscar informações e a utilizá-las em seu processo cotidiano de tomada de decisão, em diferentes áreas do conhecimento.

Os casos apresentados são histórias construídas, englobando personagens que se movimentam em torno de uma situação central e de uma seqüência de eventos desencadeados por ela. Configuram-se em estruturas bastante flexíveis para abarcar o conhecimento prático, as deduções lógicas, os julgamentos e as tomadas de decisão no exercício cotidiano da assistência à saúde. Algumas vezes o enredo é o mais importante, em outras, o detalhe, a mensagem subjacente ou a parábola que ressoa com as experiências e sentimentos do ouvinte/leitor representam a mensagem principal $^{9}$.

A matéria prima utilizada na confecção dessa modalidade narrativa tangencia o real e o imaginado, tecendo a trama de histórias que buscam apresentar o caso típico, localizado em contextos específicos.
Portanto, a aprendizagem baseada em problemas, apontada como uma alternativa aos métodos didáticos convencionais, traz algumas vantagens, tais como: aumento da retenção de informação; desenvolvimento de uma base de conhecimento integrada; encorajamento em direção ao aprendizado como algo a ser construído ao longo da vida; maior exposição à experiência clínica, inclusive, em estágios mais precoces do currículo; aumento da vinculação estudante e profissional e da motivação geral ${ }^{10}$. Esses parecem ser argumentos convincentes para a utilização dessa modalidade pedagógica em larga escala, inclusive porque o exercício da clínica traz cotidianamente ao médico a tensão inevitável, ocasionada pela oposição constante entre subjetividade/objetividade, singularidade/universalidade, doente/ doença ${ }^{11}$.

\section{2 - Narrativas de pacientes sobre suas doenças}

As narrativas de pacientes abordam aspectos da vida, discussões sobre a doença e desequilíbrios por ela impostos e, especialmente, são apresentados depoimentos sobre as capacidades individuais de agir para transformar essas novas realidades.

Kleinman ${ }^{12}$, criador da expressão ilness narratives, postula que essa modalidade é a forma pela qual os pacientes modelam e dão sentido aos seus sofrimentos. Frank ${ }^{13}$ afirma que a pessoa que revela a sua doença por meio de uma história transforma fato em experiência; a mesma doença que situa o corpo à parte das outras pessoas, na narrativa transforma-se no elo comum de sofrimento que une corpos em suas vulnerabilidades compartilhadas.

Hawkins ${ }^{14}$, com base em seu trabalho, centrado em patografias, isto é, narrativas escritas por pacientes e posteriormente publicadas, propõe que três tipos de argumentação estão presentes nesse gênero literário: a "didática", baseada numa experiência vivida que é passada aos outros, no sentido de infundirlhes confiança e esperança; a "irritada", que se volta contra a dor produzida nos corpos pelas técnicas médicas invasivas e, finalmente, o tipo de argumentação que qualifica como "de positividade da mente", que toma a defesa da necessária integração corpo/mente, reconhecendo as funções curativas das maneiras positivas de pensar.

A atual ênfase nas narrativas de pacientes parece ter sido impulsionada por mudanças ocorridas nos padrões de morbidade. O relativo declínio de importância das doenças infecciosas, nas quais se fundava o modelo biomédico, somado ao crescimento do impacto das doenças crônicas e degenerativas, determinou uma renegociação do papel do profissional de saúde no cuidado de seus pacientes. As narrativas ganharam relevância no estudo de doenças crônicas como um recurso para o entendimento do esforço empreendido pelos pacientes para lidar com suas situações de vida cotidiana e, acima de tudo, com os proble- 
mas de identidade que a doença gera. Como diz Morris ${ }^{15}$, cujos trabalhos centram-se na noção por ele chamada "biocultural" das doenças, a narrativa jamais substituirá o laser, mas ajuda a apreender os fatores ambientais que provocam as enfermidades e auxilia pessoas que sofrem de doenças incuráveis, para as quais o uso exclusivo de medicação não se mostra eficaz.

Outros fatores também tiveram importância para a valorização da narrativa como parte epistemológica da construção do saber médico, entre eles, a maior difusão de informações sobre as doenças e os debates públicos sobre a efetividade da Medicina.

As narrativas sobre doenças, segundo Bury ${ }^{16}$, enquadramse em três grupos: narrativas contingentes, morais e centrais. As primeiras apresentam créditos sobre as origens da doença, as causas imediatas do evento mórbido e sobre os efeitos subseqüentes do adoecimento na vida cotidiana. As narrativas morais proporcionam descrições das mudanças mediadas pela relação indivíduo, doença e identidade social, bem como dos mecanismos de (re)estabelecimento do status moral ou de manutenção de uma distância social. As últimas revelam conexões entre as experiências leigas particulares e níveis mais profundos de significado ligados ao sofrimento e à doença.

Hydén ${ }^{17}$ afirma que o interesse dos pesquisadores em narrativas tem sido focado em como as pessoas falam e apresentam eventos e não somente naquilo que é dito. Há uma crescente convicção de que a narrativa não é simplesmente um meio razoavelmente transparente e neutro para conduzir algo que se situa além da linguagem e da história. Particularmente, a forma da narrativa, sua apresentação e organização, também transportam algo sobre a auto-imagem que o narrador espera conduzir ao ouvinte (leitor).

Numa perspectiva sociológica, este autor entende as narrativas como produtos sociais e culturais, expressões do sofrimento dos pacientes acometidos pelas doenças e, especialmente, sobre suas tentativas de reconstrução de suas vidas.

\section{3 - Narrativas disponíveis em materiais informativos}

Os materiais informativos (cartilhas, folhetos, websites, cartazes, dentre outros) dirigidos ao público leigo - pacientes, familiares e curiosos - representam a interface entre a cultura científica e a literária. Necessitam, ao mesmo tempo, de clareza e objetividade, a ponto de possibilitar uma comunicação auto-explicativa, mas não podem estar revestidos por uma moldura asséptica e distante. Em geral, apresentam projeto gráfico cuidadoso e adequado ao público-alvo. Essa modalidade narrativa inclui exposições, discussões, explanações, descrições e processos. Cada um desses gêneros tem diferentes funções e propósitos. As exposições apresentam um ângulo de uma argumentação, usualmente com a finalidade de atrair o leitor para um determinado ponto de vista; as discussões exploram os dois lados de um argumento; as explanações explicam algo ao leitor; as descrições detalham as particularidades de alguém ou alguma coisa e os processos proporcionam instruções passo a passo sobre como realizar algo ${ }^{18}$.

\section{4 - Anamneses sistematizadas em prontuários}

Da história clínica, registrada em formato padrão, com mínimas variações, constam: informações de identificação, queixa principal, história da doença atual, história patológica pregressa, revisão dos sistemas, história familiar e história social. A parte central do relato, a história da doença atual, apresenta uma narrativa. Ela organiza as queixas do paciente em uma série de pistas diagnósticas lógicas.

Entretanto, essa modalidade narrativa, a primeira escuta, não soa como história. Sua tradução da experiência real de adoecimento não se assemelha à vida do paciente: "JRN, sexo masculino, branco, 77 anos, queixa-se de dor e hiperemia conjuntival no olho direito há um dia, com piora da acuidade visual há um mês." tem o tom rotineiro dos registros oficiais e burocráticos, cujos narradores são apagados e cuja tonalidade é imutável e objetiva. A aflição que levou o senhor JRN a procurar atendimento está formatada em um recontar médico, versão aplanada da história original. Os motivos que o levaram a procurar atendimento podem ter sido a interferência em sua atividade de trabalho ou na vida familiar, ou ainda, simplesmente, o medo de que desta vez "a coisa seja séria".

A experiência do paciente é codificada em um diagrama com o objetivo de eliminar as "irrelevâncias" e iluminar os conceitos fisiopatológicos.

Cardoso ${ }^{19}$ diz ser o prontuário o depositário da primeira narrativa médica; é com base nele que os casos médicos são apresentados. Texto, imagem, números e gráficos se misturam em uma narrativa "econômica", mas inegavelmente individualizada. Além dos eventos relacionados à doença, constam informações sobre inserção social, hábitos alimentares, bem como, de forma direta ou indireta, são estabelecidas relações causais entre os eventos selecionados.

\section{5 - Relatos de casos em sessões clínicas/ casos apresentados em revistas científicas}

Apesar dos avanços no conhecimento biomédico, o estudo de casos particulares continua sendo a base para a educação médica e identificação de problemas para os quais as pesquisas serão aplicadas. Constituem-se no meio pelo qual médicos comunicam uns aos outros seu entendimento a respeito de pacientes individualizados e seus problemas médicos, o que foi feito para investigá-los e solucioná-los. 
Hunter ${ }^{4}$ afirma que as apresentações de casos seguem rigorosamente convenções previamente estabelecidas; são narrativas estritamente ordenadas, em linguagem descritiva e de pobre tonalidade. Essa conformação permite a ocorrência de um distanciamento emocional, considerado necessário para o cuidado do paciente, bem como ressalta os padrões de evidência, o que, em última instância, possibilitará a identificação do enigma posto pela doença.

As apresentações de caso procuram verter a interpretação individual do médico da experiência de adoecimento do paciente, subjetiva e privada, em uma outra, objetiva e científica. Por um outro ponto de vista, trata-se de uma tentativa de transformação do sofrimento do paciente em uma versão medicamente reconhecível e confiável ${ }^{4}$.

Tradicionalmente o conhecimento médico, desde Hipócrates até hoje, é desenvolvido e transmitido via relatos de casos. Na acepção da epidemiologia contemporânea, são conceituados como apresentações detalhadas de um único caso ou de poucos casos e representam uma forma importante de trazer doenças, especialmente aquelas mais raras, ao conhecimento médico.

Segundo Donnelly ${ }^{20}$, as apresentações de caso encerram práticas de linguagem problemáticas:

- Introdução da pessoa enferma meramente como um espécime biológico. Essa caracterização do paciente descreve-o exclusivamente em termos de seu transtorno biológico.

- Tradução da queixa principal do paciente em linguagem biomédica.

- Utilização de artifícios retóricos que, de forma repetitiva, elevam a credibilidade dos médicos e dos exames laboratoriais e lançam dúvidas a respeito da confiabilidade dos testemunhos dos pacientes. Nesses relatos o paciente "fala", "refere", "declara", "afirma", "nega"; em contraste, os médicos "registram", "observam", "encontram". Nas informações derivadas de exames complementares são utilizadas as expressões "demonstram", refletindo a atribuição de uma revelação científica, independente de interpretação. Um outro dispositivo pretensioso repetidamente usado é a voz passiva. Por exemplo, "o baço foi palpado", em vez de "palpei o baço".

Charon $^{3}$ diz que embora o médico tenha pretensões de estar distanciado e ser onisciente em suas narrativas, é inegável o fato de que ele "habita" seu set de motivos, medos, esperanças e que, conseqüentemente, a narrativa por ele produzida é limitada por seu ângulo de visão e está sempre sendo engendrada com base nas seguintes características:

- A conversão da história do paciente em relatos focados exclusivamente no estabelecimento e curso da disfun- ção biológica atual. A exclusão das percepções e entendimento do paciente a respeito de sua doença e seus efeitos na vida cotidiana aponta para uma postura que desconsidera os medos, as dúvidas e o sofrimento.

- A categorização daquilo que é dito pelo paciente como subjetivo, em contraposição à objetividade dos achados de exame físico e resultados laboratoriais.

- A transformação dos pensamentos e sentimentos dos pacientes em elementos patológicos; por exemplo, "tristeza" traduzida em "depressão".

- A falência em registrar importantes mudanças na perspectiva do paciente, por exemplo, as opiniões de pacientes portadores de doenças terminais a respeito de permanência em unidades de terapia intensiva e a realização de manobras invasivas.

\section{LITERATURA E MEDICINA}

Hunter ${ }^{4}$ afirma, de forma categórica, que a Medicina não é uma ciência. Ela é interpretativa e não simplesmente baseada em fatos; a capacidade de identificar-se com algo e intuir pode ser tão importante no diagnóstico e tratamento quanto o são os dados científicos e a dedução lógica. Portanto, como a Literatura, diz respeito a pessoas e suas histórias e participa de forma tácita e explícita em valores culturais, concepções e ideologias.

Charon $^{3}$ postula que ensinar estudantes de Medicina a examinar os elementos de narrativas literárias prepara-os para leituras disciplinadas das "caóticas" narrativas médicas, quer sejam prontuários, imagens diagnósticas, histórias narradas pelos pacientes, exames físicos ou cursos clínicos das doenças. Afirma que registros literários de experiências de doença podem ensinar lições concretas e poderosas sobre as vidas dos indivíduos doentes, bem como permitir aos médicos reconhecer a força e as implicações de seus atos.

As afirmações dessas duas autoras servem de substrato para a argumentação de Verguese ${ }^{21}$. Os médicos, segundo ele, muito se beneficiariam com o estudo de algumas ferramentas que os escritores utilizam, visto que tanto as narrativas literárias quanto as médicas necessitam de três " $\mathrm{D}$ " - drama, desire, danger para se constituírem. Ao procurar um médico, o paciente vive o seu drama particular, tem o desejo de não escutar más notícias e, invariavelmente, sente medo. As narrativas médicas, portanto, mais do que traduzirem um conflito e sua resolução devem abarcar uma epifania, em última instância, sua razão de existir. Afirma que o grande desafio do médico é comprometer-se com o paciente e sua família e encontrar esta "revelação", mesmo que ela seja simplesmente o entendimento de que não há nada mais a ser feito sob o ponto de vista da Medicina. 
As preocupações desse autor se estendem à pobreza de metáforas na Medicina moderna. As novas doenças, por exemplo, a AIDS, têm consumido muita atenção por parte dos médicos, mas muito poucas metáforas têm sido geradas por ela. Assegura que essa ausência é um triste reflexo dos novos tempos tecnológicos, uma sugestão de que o "romance da Medicina" atrofiou e de que a capacidade de observar atentamente e criar já não está mais tão evidente.

Essa constatação nos alerta para o perigo de rompimento de uma necessária integração entre teoria e prática na Medicina. Para tratar de assunto de fundamental importância, Castiel22 faz uso de uma metáfora - a imagem mitológica de Janus com suas duas faces. Para ele, "a face ciência" 22 busca estabelecer relações estáveis entre fenômenos que podem ser imbuídos de caráter geral através de leis imutáveis, tendo como premissas precisão e capacidade de replicação. A outra, aquela da "sabedoria prática" 22, é um modo de agir no mundo, carreando em si a necessidade de lidar com particularidades impossíveis de serem transmutadas em leis universais.

O campo da Literatura e Medicina foi introduzido nas escolas médicas americanas em 1972. Essa iniciativa foi fruto da ampla reflexão sobre como enfrentar o desafio da educação médica de integrar excelência técnica e traços humanistas. Os cursos propostos têm ênfases em variadas áreas e utilizam-se de fontes diversas em seu desenvolvimento.

Donohoe ${ }^{23}$, por exemplo, desenhou um curso que combina literatura (histórias curtas, ensaios e novelas) com artigos extraídos de periódicos médicos contemporâneos, para promover a discussão sobre os determinantes sociais, econômicos e culturais das doenças.

Soricelly, médica, e Flood, professor de Literatura ${ }^{24}$, montaram uma disciplina com o objetivo de explorar as questões de gênero na Medicina.

Blasco $^{25}$, da Universidade de Santo Amaro, descreve em um artigo sua experiência no projeto Literatura e cinema para estudantes de Medicina em que quarenta estudantes de primeiro ao quinto ano da graduação, de diversas escolas médicas do estado de São Paulo, discutiram, com base em obras literárias e filmes, a figura do médico; o paciente e o sofrimento humano; doenças, limitações e insanidades; ética e relações humanas.

\section{PAPEL DA NARRATIVA NA ÉTICA MÉDICA}

Os médicos confrontam-se com vários dilemas no exercício da clínica: morais, éticos, legais, sociais, religiosos e econômicos. Nessas ocasiões, questionam seus próprios valores. Ao escutar atentamente as histórias de pacientes, os profissionais de saúde ampliam suas perspectivas, organizam e inte- gram situações complexas, o que os auxilia na condução dessas situações difíceis.

Os objetos e temas da ética no campo específico da Medicina têm sofrido mudanças desde que a Biomedicina passou a assumir feições tecnobiocientíficas, com o desenvolvimento exponencial de novos recursos técnicos dirigidos especialmente ao diagnóstico e ao tratamento ${ }^{26}$. Assim, além dos dilemas morais tradicionais concernentes à clínica - problemas do nascer, viver, adoecer e morrer -, essas circunstâncias criaram situações geradoras de novos problemas éticos.

A abordagem narrativa de questões éticas revela os eventos individuais da experiência de adoecer em todas as suas contradições e significados, para interpretação e entendimento. Os dilemas morais são postos na moldura da biografia e da cultura do paciente.

Segundo Rubin ${ }^{27}$, o método de construção de narrativas pode aguçar o juízo a respeito dos aspectos relacionados à forma como são construídas as narrativas de um caso ou de um dilema ético, das vozes às quais é dada autoridade, dos planos considerados relevantes e, por último, das possíveis soluções consideradas. A virtude da abordagem narrativa é o fato de sua utilização forçar os profissionais de saúde a exporem suas concepções e preconceitos, confrontá-los e, em última instância, trazer lealdade para o diálogo com o outro.

\section{UMA NOVA FORMAÇÃO E UMA “VELHA" NOVA ESPISTEMOLOGIA NARRATIVA}

Nas últimas décadas, a preocupação com a capacitação dos profissionais de saúde é uma realidade. As modificações no perfil de morbi-mortalidade, bem como, a avalanche de novas informações, em velocidade jamais vista anteriormente, têm levado a profundas reflexões sobre essa temática.

A ênfase da formação médica passou a estar centrada na interpretação de exames cada vez mais complexos e na prescrição de drogas potentes. Entretanto, os pacientes oferecem seus relatos pessoais em troca de cuidado; não estão apenas procurando o manejo de seus sintomas e um lugar seguro para o tratamento, querem, além disso, entender e dar significado às suas próprias histórias ${ }^{28}$.

O temor por uma forma tecnicista de encarar a prática profissional é constatado nas recomendações das Diretrizes Curriculares Nacionais do curso de graduação em Medicina, de 2001. Estas sugerem a inclusão curricular de dimensões éticas e humanísticas que desenvolvam no aluno atitudes e valores orientados para a cidadania ${ }^{29}$.

A questão acima abordada ultrapassou os limites disciplinares estando em foco em publicações dirigidas ao público em geral, como o The New York Times ${ }^{30}$ e a Revista Veja ${ }^{31}$. 
Na primeira, em artigo intitulado "Diagnosis goes low tech", discute-se a importância da exposição dos estudantes de Medicina às humanidades, ensinando-os a prestar atenção às palavras dos pacientes, bem como, a entenderem a forma pela qual as emoções do profissional afetam suas percepções e, em última instância, sua prática clínica. Nele, Rita Charon, diretora do Departamento de Humanidades da Universidade de Columbia, afirma que as escolas médicas não têm a capacidade de treinar alunos em empatia, mas assegura ser possível e, acima de tudo, ser obrigação dos educadores equipar os estudantes com a habilidade de enxergar, articular, reter e compreender a posição dos pacientes.

No artigo da revista Veja, intitulado "Médicos aprendem a escutar os pacientes", além de se ressaltar a importância da história contada pelo paciente e da compreensão da essência desse relato, a jornalista afirma: "(...) a Medicina narrativa é uma miragem num sistema de saúde precário como o brasileiro."31

Little 32 afirma que o surgimento da expressão Medicina humanística revela um movimento de repensar as dificuldades enfrentadas pelos serviços de saúde na maioria das sociedades do dito primeiro mundo. Aponta diversos fatores que atestam essa crise: profissionais de saúde apresentam altas taxas de incidência de doenças relacionadas ao estresse e da ordem da saúde mental, inclusive com índices de suicídio maior do que em outros grupos; litígios médicos continuam em expansão e representam um custo alarmante; as despesas com serviços e tecnologia caminham para um limite proibitivo de tolerância, na maioria dos países ocidentais; recursos humanos, físicos e tecnológicos estão distribuídos de maneira desigual; altos investimentos em tecnologia produzem resultados diminutos na saúde da população e, finalmente, mas não menos importante, o fato dos indivíduos que se sentem enfermos procurarem cada vez mais práticas de Medicina alternativa, por se sentirem mais bem ouvidos e cuidados, do que na Medicina convencional.

Narrar é uma manifestação que acompanha o homem desde a sua origem. As narrativas estão estruturadas sobre cinco elementos, quais sejam: os fatos, as personagens, o tempo, o espaço e o narrador. Este último configura-se como o elemento organizador de todos os outros componentes, o intermediário entre o narrado e o autor, entre o narrado e o leitor.

Este artigo apresentou com ênfase o narrador-médico, o narrador-Sherlock Holmes, ativo participante do "círculo diagnóstico", como o apresenta Hunter ${ }^{4}$. Em uma perspectiva dialógica bakhtiniana, ele é peça chave no caráter coletivo da produção de narrativas sobre as experiências de adoecimento de seus pacientes

Nessa tarefa eminentemente interpretativa, o médico é, ao mesmo tempo, leitor e narrador, decodificador de pala- vras e de corpos repletos de signos. A partir de um outro conceito bakhtiniano, heteroglossia ou plurilinguismo, os signos não apenas refletem o mundo, mas também o refratam, isto é, com nossos signos, além de descrevermos o mundo, construímos diversas interpretações (refrações) dele, fruto do caráter múltiplo e heterogêneo das experiências concretas dos grupos humanos. Nessa mescla de histórias, signos, reflexões e refrações são então construídas as narrativas em Medicina.

Utilizando as ferramentas da crítica literária, distinguemse variantes do narrador: o que está fora dos fatos narrados, o narrador observador, geralmente onisciente, e um outro, o narrador personagem, testemunha ou protagonista. Conforme evidenciado na apresentação sobre as diferentes modalidades narrativas, percebe-se que há uma variação nas posições adotadas pelo narrador-médico, bem como, no tipo de linguagem por ele utilizada. Narrativas emocionadas que visam atrair a platéia; narrativas formais, em prol de um texto dito científico; narrativas vacilantes, pela dificuldade de estabelecimento de hipóteses diagnósticas, e narrativas impessoais, armaduras protetoras contra o envolvimento emocional são algumas das variantes observadas.

\section{CONSIDERAÇÕES FINAIS}

As pessoas expressam-se pelo olhar, pelo toque, pela fala, pelo corpo, até pela "não expressão". Aventurar-se nesse universo exige dos profissionais de saúde encontrarem formas adequadas de olhar, ouvir, sentir e interpretar. Para isso, não poderão lançar mão de "receitas prontas e universais", desvalorizando as singularidades de cada um e as diversidades atreladas a contextos sócio-culturais plurais.

Em artigo da Folha de São Paulo, Ivan Miziara ${ }^{33}$, médico, jornalista e poeta afirma:

“Uma das explicações que os estudiosos da prática médica postulam para a "perda de humanidade" na relação entre médicos e doentes é que, ao preferir viver em simbiose com as máquinas e as mais modernas drogas, em detrimento de seu relacionamento pessoal com os pacientes (transformados em meros objetos de estudo), o médico tende a desvalorizar seu papel de agente ativo da cura, tornando-se, por ironia, ele também um simples objeto"

Em relação à simbiose homem-máquina, Haraway ${ }^{34}$ nos alerta que as novas tecnologias não são apenas ferramentas, próteses ou extensões para os sentidos; mas sim nos oferecem novas possibilidades de experiência e espacialidade, reconfigurando os conceitos de humano e de máquina, estabe- 
lecendo novas formas de interação que se caracterizam por não respeitar as fronteiras antológicas humano/tecnologia; interior/exterior; pensante/não pensante.

Dimensões éticas e humanísticas, educação dos sentidos, sujeitos e subjetividades são algumas das tantas maneiras de expressão da pungente necessidade de inclusão de tais dimensões no cotidiano do trabalho médico. A distinção entre "doença" e "estar doente" é destacada na língua inglesa, quando se distingue "disease" (doença) de "illness" (estar doente). Se o profissional de saúde não se acercar do mundo do paciente, lidará apenas com uma doença. A ênfase nas narrativas em Medicina parece ser um caminho profícuo para aproximar o médico do mundo do paciente, a ajudá-lo a entender o que a doença representa para cada indivíduo em particular.

O modelo biomédico, portanto, obscurece e menospreza aspectos emocionais, sociais e culturais da doença. Ao enfocar a atividade de contar histórias e suas múltiplas interpretações como cerne da prática clínica, as narrativas literárias apresentam-se como importantes ensinamentos da arte da comunicação médico-paciente. Entretanto, apesar desta certeza, inclusive já apontada em diretrizes oficiais sobre conteúdos do currículo de graduação em Medicina, as iniciativas ainda são incipientes nas Escolas Médicas brasileiras.

A literatura brasileira, com toda a sua riqueza, auxiliará os profissionais de saúde na compreensão dos labirintos da psicologia humana e dos mecanismos da vida social. Configura-se, assim, como um valioso instrumento de aquisição de conhecimento para um melhor encaminhamento de dilemas técnicos e éticos presentes no cotidiano do exercício profissional.

Bacamarte, personagem da obra "O Alienista" de Machado de Assis $^{35}$, entrega-se de corpo e alma à ciência, ignora sua família, o homem como indivíduo e a sociedade. Interfere na vida da pacata cidade de Itaguaí com a idéia de criar um manicômio, que lhe seria um meio de estudar os limites entre razão e loucura.

Manuel Bandeira, ${ }^{36}$ no poema Pneumotórax, fala da vida que poderia ter sido e não foi. O paciente, vítima de febre, hemoptise, dispnéia e suores chama o médico que, na impossibilidade de adotar uma conduta terapêutica medicamentosa ou manobras invasivas salvadoras (pneumotórax), diz ao paciente que a unica coisa a fazer é tocar um tango argentino.

Fabrício, funcionário de uma repartição pública, gostava muito de Zizinha. Um dia, recebeu uma carta de sua amada, participando-lhe que o pai resolvera passar um mês em Caxambu, com a família, e pedindo-lhe que também fosse, pois ela não teria forças para viver tão longe dele. Ao solicitar uma licença para viajar, frente às dificuldades encontradas, alegou estar doente. Ao procurar o médico para a concessão de um atestado, apesar de não se sentir doente e apenas adotar um disfarce, recebe o diagnóstico de "cardialgia sintomática da diátese artrítica". Essas palavras enigmáticas tiveram um grande efeito sobre ele, febre e mal estar que duraram vinte dias ${ }^{37}$.

Os enredos e personagens de Machado de Assis, Manuel Bandeira e Artur Azevedo constituem-se em fontes que propiciam o levantamento de questões a serem refletidas sob o ponto de vista da responsabilidade social, da ética e das relação médico-paciente.

Segundo Birman ${ }^{38}$, a subjetividade é inequivocamente uma das matérias primas do campo da educação; em torno dela giram as engrenagens desse campo com suas práticas e finalidades. Afirmamos, da mesma forma, sem temor, que o exercício clínico há que se valer do instrumental técnico-científico objetivo atrelado às interpretações e intuições dos médicos.

\section{REFERÊNCIAS}

1. Greenhalgh T, Hurwitz B. Why study narrative? In: Greenhalgh T, Hurwitz B, editors. Narrative Based Medicine. London: British Library; 2000. p.3-16.

2. Kottow M. Literary narrative in medical practice. J Med Ethics: Medical Humanities. 2002; 28: 41-4.

3. Charon R. Literary Concepts for Medical Readers: Frame, Time, Plot, Desire. In: Hawkins AH, McEntyre MC, editors. Teaching literature and medicine. New York: Modern Language Association of America; 2000. p.29-42

4. Hunter KM. Doctor's stories. The narrative structure of medical knowledge. Princeton: University of Princeton Press; 1991.

5. Hawkins AH, Mcentyre MC. Teaching literature and medicine. New York: The Modern Language Association of America; 2000.

6. Scliar MJ. da Bíblia à psicanálise: saúde, doença e Medicina na cultura Judaica. [Tese]. Rio de Janeiro: Escola Nacional de Saúde Pública, Fundação Oswaldo Cruz; 1999.

7. Poirier S. Voice in the medical narrative. In: Charon R, Montello M, editors. The role of narrative in medical ethics. New York/London: Routledge; 2002. p. 48-58.

8. Charon R. Narrative and medicine. N Engl J Med. 2004; 350 (9): 862-4.

9. Cox K. Stories as case knowledge: case knowledge as stories. Med Educ. 2001; 35: 862-6.

10. Robbs J, Meredith S. 1994. The problem- based learning curriculum at Southern Illinois University School of Medicine [online] 1994. Available from: http:// www.suimed.edu/pblc/pblcur.html (link no longer active) 
11. Souza ARND. Formação médica, racionalidade e experiência: o discurso médico e o ensino da clínica. [Tese de Doutorado]. Rio de Janeiro: Instituto de Psiquiatria da Universidade Federal do Rio de Janeiro; 1998.

12. Kleinman A. The illness narratives. Suffering, healing \& the human condition. New York: Basic Book; 1988.

13. Frank A. The wounded storyteller. Body, illness and ethics. Chicago: The University of Chicago Press; 1995.

14. Hawkins AH. Reconstructing illness. Studies in pathography. $2^{\text {nd }}$ ed. Indiana: Perdue University Press; 1999

15. Morris DB. Illness and culture in the postmodern age. Berkeley/Los Angeles/London: The University of California Press; 1998.

16. Bury M. Illness narratives: fact or fiction? Sociol Health Illn. 2001; 23 (3): 263-85.

17. Hydén L. Illness narrative. Sociol Health Illn. 1997; 19 (1): 49-64.

18. Jordens CFC, Little M. 'In this scenario, I do this, for these reasons': narrative, genre and ethical reasoning in the clinic. Soc Sci Med. 2004; 58: 1635-45.

19. Cardoso MHCA. A herança arcaica de um modelo: história, Medicina... e a síndrome de Down. [Tese]. Rio de Janeiro: Programa de Pós-Graduação em Saúde da Criança e da Mulher, Instituto Fernandes Figueira, Fundação Oswaldo Cruz; 2000.

20. Donnelly W. The language of medical case histories. Ann Intern Med. 1997; 127 (11): 1045-8.

21. Verguese A. The physician as storyteller. Ann Intern Med. 2001; 135 (11): 1012-7.

22. Castiel LD. a medida do possível...Saúde, risco e tecnobiociências. Rio de Janeiro: Editora Fiocruz/ Contra Capa Livraria; 1999.

23. Donohoe M. Exploring the human condition: literature and public health issues. In: Hawkins AH, McEntyre MC, editors. Teaching literature and medicine. New York: The Modern Language Association; 2000. p.92-104.

24. Soricelli RL, Flood DH. (Un)professional relationships in the gendered maze and medicine. In: Hawkins AH, McEntyre MC, editors. Teaching literature and medicine. New York: The Modern Language Association; 2000. p. 344-52.

25. Blasco PG. Literature and movies for medical students. Fam Med. 2001; 33 (6): 426-8.

26. Castiel LD. Insegurança, ética e comunicação em saúde pública. Rev Saúde Pública. 2003; 37(2):161-7.

27. Rubin SB. Beyond the authoritative voice: casting a wide net in ethics consultation. In: Charon R, Montello M, editors.
Stories Matter: The Role of Narrative in Medical Ethics. New York/London: Routledge; 2002. p. 109-18.

28. Gaydos HL. Understanding personal narratives: an approach to practice. J Adv Nurs. 2005; 49(3), 254-9.

29. Conselho Nacional de Educação/Câmara de Educação Superior. Resolução $n^{\circ} 4$ institui diretrizes curriculares nacionais do curso de graduação em Medicina. Diário Oficial da União 2001; 7 nov.

30. Smith D. Diagnosis Goes Low Tech. The New York Times on Web [journal on line] 2003. Available from: http:// $\mathrm{n}$ a r r a t i v e m e d i cin e.org/p res s/ DiagnosisGoesLowTech.html/.

31. Buchalla AP. Médicos aprendem a escutar os pacientes. Veja. 2004 mai 5; geral: 85.

32. Little JM. Humanistic medicine or values-based medicine... what is in a name? Med J Aust. 2002; 177(6): 319-321.

33. Miziara I. Leituras cruzadas: o médico-objeto. Folha on-line [jornal on line] 2003. Disponível em: http:// www1.folha.uol.com.br/folha/sinapse/ult1063u355.shtml/.

34. Haraway D. Modest_Witness@SecondMillenium.FemaleMan ${ }^{\odot}$ meetsoncomouse ${ }^{\mathrm{TM}}$. Feminism and technoscience. New York/London: Routledge; 1997.

35. Assis M. O alienista. São Paulo: FTD Editora; 1994.

36. Bandeira M. Poesia completa e prosa. Rio de Janeiro: Cia. José Aguilar; 1967.

37. Azevedo A. Contos cariocas. Livro posthumo. Rio de Janeiro: Freitas Bastos; 1928.

38. Birman J. Subjetividade, contemporaneidade e educação. In: Candau VM, organizadora. Cultura, linguagem e subjetividade no ensinar e aprender. Rio de Janeiro: DP\&A; 2000. p. 11-28.

\section{Endereço para correspondência}

Eloísa Grossman

Núcleo de Estudos da Saúde do Adolescente.

Boulevard 28 de Setembro 109 - Pavilhão Floriano

Stoffel, - Vila Isabel,

CEP 20551-030 - Rio de Janeiro - Brasil

e-mail: egrossman@openlink.com.br 